\title{
Total Domination Number and Chromatic Number of a Fuzzy Graph
}

\author{
S. Vimala \\ Assistant Professor \\ Department of Mathematics \\ Mother Teresa Women's University, Kodaikanal
}

\author{
J. S. Sathya \\ Research Scholar \\ Department of Mathematics \\ Mother Teresa Women's University, Kodaikanal
}

\begin{abstract}
A subset $\mathrm{S}$ of $\mathrm{V}$ is called a domination set in $\mathrm{G}$ if every vertex in $\mathrm{V}-\mathrm{S}$ is adjacent to at least one vertex in $\mathrm{S}$. A dominating set is said to be Fuzzy Total Dominating set if every vertex in V is adjacent to at least one vertex in S. Minimum cardinality taken over all total dominating set is called as fuzzy total domination number and is denoted by $\gamma_{f t}(\mathrm{G})$. The minimum number of colours required to colour all the vertices such that adjacent vertices do not receive the same colour is the chromatic number $\chi(\mathrm{G})$. For any graph $\mathrm{G}$ a complete sub graph of $G$ is called a clique of $G$. In this paper we find an upper bound for the sum of the fuzzy total domination and chromatic number in fuzzy graphs and characterize the corresponding extremal fuzzy graphs.
\end{abstract}

\section{General Terms}

$\mathrm{G}(\mu, \sigma)$ be simple undirected fuzzy graph

\section{Keywords}

Fuzzy Total Domination Number, Chromatic Number, Clique, Fuzzy Graphs

\section{INTRODUCTION}

The study of dominating sets in graphs was begun by Ore and Berge, the domination number, total domination number are introduced by Cockayne and Hedetniemi. A Mathematical framework to describe the phenomena of uncertainty in real life situation is first suggested by L.A.Zadeh in 1965 .

Research on the theory of fuzzy sets has been witnessing an exponential growth; both within mathematics and in its applications. This ranges from traditional mathematical subjects like logic, topology, algebra, analysis etc. consequently fuzzy set theory has emerged as potential area of interdisciplinary research and fuzzy graph theory is of recent interest.

The fuzzy definition of fuzzy graphs was proposed by Kaufmann [4], from the fuzzy relations introduced by Zadeh [9]. Although Rosenfeld[5] introduced another elaborated definition, including fuzzy vertex and fuzzy edges. Several fuzzy analogs of graph theoretic concepts such as paths, cycles connectedness etc. The concept of domination in fuzzy graphs was investigated by A.Somasundram, S.Somasundram [6]. A. Somasundram presented the concepts of independent domination, total domination, connected domination and domination in cartesian product and composition of fuzzy $\operatorname{graphs}([7][8])$

Several authors have studied the problem of obtaining an upper bound for the sum of a domination parameter and a graph theoretic parameter and characterized the corresponding extremal graphs. In [10], Paulraj Joseph J and Arumugam S proved that $\gamma+\mathrm{k} \leq \mathrm{p}$. In[9], Paulraj Joseph $\mathrm{J}$ and Arumugam $\mathrm{S}$ proved that $\gamma_{c}(\mathrm{G})+\chi \leq \mathrm{p}+1$. They also characterized the class of graphs for which the upper bound is attained. They also proved similar results for $\gamma$ and $\gamma_{t}$. In[14], Mahadevan G introduced the concept the complementary perfect domination number $\gamma_{c p}$ and proved that $\gamma_{c p}(\mathrm{G})+\chi \leq 2 \mathrm{n}-2$, and characterized the corresponding extermal graphs. In[15], S.Vimala and J.S.Sathya proved that $\gamma_{t}(\mathrm{G})+\chi(\mathrm{G})=2 \mathrm{n}-5$. They also characterised the class of graphs for which the upper bound is attained. In this paper we obtain sharp upper bound for the sum of the fuzzy total domination number and chromatic number and characterize the corresponding extremal fuzzy graphs.

\section{PRELIMINARIES}

If $\mathrm{X}$ is collection of objects denoted generically by $\mathrm{x}$, then a Fuzzy set $\tilde{A}$ in $\mathrm{X}$ is a set of ordered pairs: $\widetilde{\mathrm{A}}=\left\{\left(\mathrm{x}, \mu_{\widetilde{\mathrm{A}}}(\mathrm{x})\right) /\right.$ $\mathrm{x} \in \mathrm{X}\}, \mu_{\widetilde{\mathrm{A}}}(\mathrm{x})$ is called the membership function of $\mathrm{x}$ in $\widetilde{\mathrm{A}}$ that maps $X$ to the membership space $M$ (when $M$ contains only the two points 0 and 1 ). Let $\mathrm{E}$ be the (crisp) set of nodes. A fuzzy graph is then defined by, $\widetilde{\mathrm{G}}\left(x_{i}, x_{j}\right)=\left\{\left(x_{i}, x_{j}\right), \mu_{\widetilde{\mathrm{G}}}\left(x_{i}, x_{j}\right) /\left(x_{i}, x_{j}\right) \in \mathrm{E} \times \mathrm{E}\right\} . \widetilde{\mathrm{H}}\left(x_{i}, x_{j}\right)$ is a Fuzzy Sub graph of $\widetilde{\mathrm{G}}\left(x_{i}, x_{j}\right)$ if $\mu_{\widetilde{\mathrm{H}}}\left(x_{i}, x_{j}\right) \leq \mu_{\widetilde{\mathrm{G}}}\left(x_{i}, x_{j}\right) \forall\left(x_{i}, x_{j}\right) \in \mathrm{E} \times \mathrm{E}, \widetilde{\mathrm{H}}\left(x_{i}, x_{j}\right) \quad$ is $\quad$ a spanning fuzzy sub graph of $\widetilde{\mathrm{G}}\left(x_{i}, x_{j}\right)$ if the node set of $\widetilde{\mathrm{H}}\left(x_{i}, x_{j}\right)$ and $\widetilde{\mathrm{G}}\left(x_{i}, x_{j}\right)$ are equal, that is if they differ only in their arc weights.

Let $\mathrm{G}(\mu, \sigma)$ be simple undirected fuzzy graph. The degree of any vertex $u$ in $G$ is the number of edges incident with $u$ and is denoted by $\mathrm{d}(\mathrm{u})$. The minimum and maximum degree of a vertex is denoted by $\delta(\mathrm{G})$ and $\Delta(\mathrm{G})$ respectively, $\mathrm{P}_{\mathrm{n}}$ denotes the path on $n$ vertices. The vertex connectivity $\kappa(\mathrm{G})$ of a graph $\mathrm{G}$ is the minimum number of vertices whose removal results in a disconnected graph. The chromatic number $\chi$ is defined to be the minimum number of colours required to colour all the vertices such that adjacent vertices do not receive the same colour. For any graph $\mathrm{G}$ a complete sub graph of $\mathrm{G}$ is called a clique of $\mathrm{G}$. The number of vertices in a largest clique of $\mathrm{G}$ is called the clique number of $\mathrm{G}$.

A subset $\mathrm{S}$ of $\mathrm{V}$ is called a dominating set in $\mathrm{G}$, if every vertex in $\mathrm{V}-\mathrm{S}$ is adjacent to at least one vertex is $\mathrm{S}$. The minimum cardinality taken over all minimal dominating sets in $\mathrm{G}$ is called the domination number of $\mathrm{G}$ and is denoted by $\gamma$. A dominating set $\mathrm{S}$ is said to be fuzzy total dominating set if every vertex in $\mathrm{V}$ is adjacent to at least one vertex in $\mathrm{S}$. Minimum cardinality taken over all total dominating set is called as fuzzy total domination number and is denoted by $\gamma_{f t}(\mathrm{G})$. We use the following previous results.

\subsection{Theorem: [1]: For any connected graph $\mathrm{G}, \gamma_{t}(\mathrm{G}) \leq n$}

2.2 Theorem: [2]: For any connected graph $\mathrm{G}, \chi(\mathrm{G}) \leq \Delta(\mathrm{G})+1$. 


\section{MAIN RESULTS}

3.1 Theorem: For any connected fuzzy graph $\mathrm{G}, \gamma_{t}(\mathrm{G})+$ $\chi(\mathrm{G}) \leq 2 \mathrm{n}$ and the equality holds if and only if $\mathrm{G} \cong \mathrm{K}_{1}$

Proof: $\quad \gamma_{t}(\mathrm{G})+\chi(\mathrm{G}) \leq \mathrm{n}+\Delta+1=\mathrm{n}+(\mathrm{n}-1)+1 \leq 2 \mathrm{n}$. $\quad$ If $\gamma_{t}(\mathrm{G})+\chi(\mathrm{G})=2 \mathrm{n}$ the only possible case is $\gamma_{t}(\mathrm{G})=\mathrm{n}$ and $\chi(\mathrm{G})=\mathrm{n}$, Since $\chi(\mathrm{G})=\mathrm{n}, \mathrm{G}=\mathrm{K}_{\mathrm{n}}$, But for $\mathrm{K}_{\mathrm{n}}, \gamma_{t}(\mathrm{G})=1$, so that $\mathrm{G} \cong \mathrm{K}_{1}$. Converse is obvious.

3.2 Theorem: For any connected fuzzy graph G, $\gamma_{t}(\mathrm{G})+\chi(\mathrm{G})=2 \mathrm{n}-1$ and the equality holds if and only if $\mathrm{G} \cong \mathrm{K}_{2}$

Proof: Assume that $\gamma_{t}(\mathrm{G})+\chi(\mathrm{G})=2 \mathrm{n}-1$. This is possible only if $\gamma_{t}(\mathrm{G})=\mathrm{n}$ and $\chi(\mathrm{G})=\mathrm{n}-1$ (or) $\gamma_{t}(\mathrm{G})=\mathrm{n}-1$ and $\chi(\mathrm{G})=\mathrm{n}$.

Case (i) Let $\gamma_{t}(\mathrm{G})=\mathrm{n}$ and $\chi(\mathrm{G})=\mathrm{n}-1$.

Since $\chi(\mathrm{G})=\mathrm{n}-1, \mathrm{G}$ contains a clique $\mathrm{K}$ on $\mathrm{n}-1$ vertices. Let $\mathrm{x}$ be a vertex of $G-K_{n-1}$. Since $G$ is connected the vertex $x$ is adjacent to one vertex $\mathrm{u}_{\mathrm{i}}$ for some $\mathrm{i}$ in $\mathrm{K}_{\mathrm{n}-1}\left\{\mathrm{u}_{\mathrm{i}}\right\}$ is $\gamma_{t}$ - set, so that $\gamma_{t}(\mathrm{G})=1$, we have $\mathrm{n}=1$. Then $\chi=0$, which is a contradiction. Hence no fuzzy graph exists.

Case (ii) Let $\gamma_{t}(\mathrm{G})=\mathrm{n}-1$ and $\chi(\mathrm{G})=\mathrm{n}$

Since $\chi(\mathrm{G})=\mathrm{n}, \mathrm{G}=\mathrm{K}_{\mathrm{n}}$, But for $\mathrm{K}_{\mathrm{n}}, \gamma_{\mathrm{t}}(\mathrm{G})=1$, so that $\mathrm{n}=2, \chi=2$ Hence $\mathrm{G} \cong \mathrm{K}_{2}$. Converse is obvious.

3.3 Theorem: For any connected fuzzy graph $\mathrm{G}$, $\gamma_{t}(\mathrm{G})+\chi(\mathrm{G})=2 \mathrm{n}-2$ and the equality holds if and only if $\mathrm{G} \cong \mathrm{K}_{3}$

Proof: Assume that $\gamma_{t}(\mathrm{G})+\chi(\mathrm{G})=2 \mathrm{n}-2$. This is possible only if $\gamma_{t}(\mathrm{G})=\mathrm{n}$ and $\chi(\mathrm{G})=\mathrm{n}-2$ (or) $\gamma_{t}(\mathrm{G})=\mathrm{n}-1$ and $\chi(\mathrm{G})=\mathrm{n}-1$ (or) $\gamma_{t}(\mathrm{G})=\mathrm{n}-2$ and $\chi(\mathrm{G})=\mathrm{n}$.

Case (i) Let $\gamma_{t}(\mathrm{G})=\mathrm{n}$ and $\chi(\mathrm{G})=\mathrm{n}-2$.

Since $\chi(\mathrm{G})=\mathrm{n}-2, \mathrm{G}$ contains a clique $\mathrm{K}$ on $\mathrm{n}-2$ vertices. Let $\mathrm{S}=\{\mathrm{x}, \mathrm{y}\} \in \mathrm{V}-\mathrm{S}$. Then $\langle S\rangle=K_{2}$ or $\overline{K_{2}}$

Subcase (a) Let $\langle S\rangle=K_{2}$ Since $\mathrm{G}$ is connected, $\mathrm{x}$ is adjacent to some $\mathrm{u}_{\mathrm{i}}$ of $\mathrm{K}_{\mathrm{n}-2}$. Then $\left\{\mathrm{x}, \mathrm{u}_{\mathrm{i}}\right\}$ is $\gamma_{t}$ - set, so that $\gamma_{t}(\mathrm{G})=2$ and hence $\mathrm{n}=2$. But $\chi(\mathrm{G})=\mathrm{n}-2=0$. Which is a contradiction. Hence no fuzzy graph exists.

Subcase (b) Let $\langle S\rangle=\overline{K_{2}}$ Since $\mathrm{G}$ is connected, $\mathrm{x}$ is adjacent to some $u_{i}$ of $K_{n-2}$. Then $y$ is adjacent to the same $u_{i}$ of $\mathrm{K}_{\mathrm{n}-2 \text {. Then }}\left\{\mathrm{u}_{\mathrm{i}}\right\} \gamma_{t}$ - set, so that $\gamma_{t}(\mathrm{G})=1$ and hence $\mathrm{n}=1$. But $\chi(\mathrm{G})=\mathrm{n}-2=$ negative value. Which is a contradiction. Hence no fuzzy graph exists, or $\mathrm{y}$ is adjacent to $\mathrm{u}_{\mathrm{j}}$ of $\mathrm{K}_{\mathrm{n}-2}$ for $\mathrm{i} \neq \mathrm{j}$. In this case $\left\{\mathrm{u}_{\mathrm{i}}, \mathrm{u}_{\mathrm{j}}\right\} \gamma_{t}$ - set, so that $\gamma_{t}(\mathrm{G})=2$ and hence $\mathrm{n}=2$. But $\chi(\mathrm{G})=0$. Which is a contradiction. Hence no fuzzy graph exists.

Case (ii) Let $\gamma_{t}(\mathrm{G})=\mathrm{n}-1$ and $\chi(\mathrm{G})=\mathrm{n}-1$.

Since $\chi(\mathrm{G})=\mathrm{n}-1, \mathrm{G}$ contains a clique $\mathrm{K}$ on $\mathrm{n}-1$ vertices. Let $\mathrm{x}$ be a vertex of $G-K_{n-1}$. Since $G$ is connected, $x$ is adjacent to one vertex $u_{i}$ for some $i$ in $K_{n-1}$, so that $\gamma_{t}(G)=1$, we have $\mathrm{n}=2$. Then $\chi=1$, which is a contradiction. Hence no fuzzy graph exists.

Case (iii) Let $\gamma_{t}(\mathrm{G})=\mathrm{n}-2$ and $\chi(\mathrm{G})=\mathrm{n}$

Since $\chi(G)=n, G=K_{n}$, But for $K_{n}, \gamma_{t}(G)=1$, so that $n=3, \chi=$ 3 Hence $\mathrm{G} \cong \mathrm{K}_{3}$. Converse is obvious.
3.4 Theorem: For any connected fuzzy graph $\mathrm{G}, \gamma_{t}(\mathrm{G})+$ $\chi(\mathrm{G})=2 \mathrm{n}-3$ and the equality holds if and only if $\mathrm{G} \cong \mathrm{P}_{3}, \mathrm{~K}_{4}$

Proof: Assume that $\gamma_{t}(\mathrm{G})+\chi(\mathrm{G})=2 \mathrm{n}-3$. This is possible only if $\gamma_{t}(\mathrm{G})=\mathrm{n}$ and $\chi(\mathrm{G})=\mathrm{n}-3$ (or) $\gamma_{t}(\mathrm{G})=\mathrm{n}-1$ and $\chi(\mathrm{G})=\mathrm{n}-2$ (or) $\gamma_{t}(\mathrm{G})=\mathrm{n}-2$ and $\chi(\mathrm{G})=\mathrm{n}-1($ or $) \gamma_{t}(\mathrm{G})=\mathrm{n}-3$ and $\chi(\mathrm{G})=\mathrm{n}$.

Case (i) Let $\gamma_{t}(\mathrm{G})=\mathrm{n}$ and $\chi(\mathrm{G})=\mathrm{n}-3$.

Since $\chi(\mathrm{G})=\mathrm{n}-3, \mathrm{G}$ contains a clique $\mathrm{K}$ on $\mathrm{n}-3$ vertices. Let $\mathrm{S}=\{\mathrm{x}, \mathrm{y}, \mathrm{z}\} \in \mathrm{V}-\mathrm{S}$. Then $\langle S\rangle=K_{3}, \overline{K_{3}}, \mathrm{~K}_{2} \cup \mathrm{K}_{1}, \mathrm{P}_{3}$

Subcase (i) Let $\langle S\rangle=K_{3}$. Since $\mathrm{G}$ is connected, $\mathrm{x}$ is adjacent to some $\mathrm{u}_{\mathrm{i}}$ of $\mathrm{K}_{\mathrm{n}-3}$. Then $\left\{\mathrm{x}, \mathrm{u}_{\mathrm{i}}\right\}$ is $\gamma_{t}$ - set, so that $\gamma_{t}(\mathrm{G})=2$ and hence $\mathrm{n}=2$. But $\chi(\mathrm{G})=\mathrm{n}-3=$ =negative value. Which is a contradiction. Hence no fuzzy graph exists.

Subcase (ii) Let $\langle S\rangle=\overline{K_{3}}$ Since $\mathrm{G}$ is connected, one of the vertices of $K_{n-3}$ say $u_{i}$ is adjacent to all the vertices of $S$ or two vertices of $\mathrm{S}$ or one vertex of $\mathrm{S}$. If $\mathrm{u}_{\mathrm{i}}$ for some $\mathrm{i}$ is adjacent to all the vertices of $S$, then $\left\{u_{i}\right\}$ in $K_{n-3}$ is a $\gamma_{t}$-set of $G$, so that $\gamma_{t}(\mathrm{G})=1$ and hence $\mathrm{n}=1$. But $\chi(\mathrm{G})=\mathrm{n}-3=$ negative value. Which is a contradiction. Hence no fuzzy graph exists. Since $G$ is connected $u_{i}$ for some $i$ is adjacent to two vertices of $S$ say $\mathrm{x}$ and $\mathrm{y}$ and $\mathrm{z}$ is adjacent to $\mathrm{u}_{\mathrm{j}}$ for $\mathrm{i} \neq \mathrm{j}$ in $\mathrm{K}_{\mathrm{n}-3}$, then $\left\{\mathrm{u}_{\mathrm{i}}, \mathrm{u}_{\mathrm{j}}\right\}$ in $\mathrm{K}_{\mathrm{n}-3}$ is $\gamma_{t}$-set of $\mathrm{G}$, so that $\gamma_{t}(\mathrm{G})=2$ and hence $\mathrm{n}=2$. But $\chi(\mathrm{G})=\mathrm{n}-3=$ negative value. Which is a contradiction. Hence no fuzzy graph exists. If $u_{i}$ for some $i$ is adjacent to $x$ and $u_{j}$ is adjacent to $\mathrm{y}$ and $\mathrm{u}_{\mathrm{k}}$ is adjacent to $\mathrm{z}$, then $\left\{\mathrm{u}_{\mathrm{i}}, \mathrm{u}_{\mathrm{j}}, \mathrm{u}_{\mathrm{k}}\right\}$ for $\mathrm{i} \neq \mathrm{j} \neq \mathrm{k}$ in $\mathrm{K}_{\mathrm{n}-3}$ is a $\gamma_{t}$-set of $\mathrm{G}$. so that $\gamma_{t}(\mathrm{G})=3$ and hence $\mathrm{n}=3$. But $\chi(\mathrm{G})=\mathrm{n}-3=0$. Which is a contradiction. Hence no fuzzy graph exists.

Subcase (iii) Let $\langle S\rangle=\mathrm{P}_{3}=\{x, y, z\}$. Since $\mathrm{G}$ is connected, $\mathrm{x}$ (or equivalently $\mathrm{z}$ ) is adjacent to $\mathrm{u}_{\mathrm{i}}$ for some $\mathrm{i}$ in $\mathrm{K}_{\mathrm{n}-3}$. Then $\left\{\mathrm{x}, \mathrm{y}, \mathrm{u}_{\mathrm{i}}\right\}$ is a $\gamma_{t}$-set of $\mathrm{G}$. so that $\gamma_{t}(\mathrm{G})=3$ and hence $\mathrm{n}=3$. But $\chi(\mathrm{G})=\mathrm{n}-3=0$. Which is a contradiction. Hence no fuzzy graph exists. If $\mathrm{u}_{\mathrm{i}}$ is adjacent to $\mathrm{y}$ then $\left\{\mathrm{u}_{\mathrm{i}}, \mathrm{y}\right\}$ is a $\gamma_{t}$ set of $\mathrm{G}$. so that $\gamma_{t}(\mathrm{G})=2$ and hence $\mathrm{n}=2$. But $\chi(\mathrm{G})=\mathrm{n}$ $3=$ negative value. Which is a contradiction. Hence no fuzzy graph exists.

Subcase (iv) Let $\langle S\rangle=\mathrm{K}_{2} \cup \mathrm{K}_{1}$ Let $\mathrm{xy}$ be the edge and $\mathrm{z}$ be the isolated vertex of $K_{2} \cup K_{1}$ Since $G$ is connected, there exists a $u_{i}$ in $K_{n-3}$ is adjacent to $x$ and $z$. Then $\left\{u_{i}\right\}$ is $\gamma_{t}$-set of $\mathrm{G}$, so that $\gamma_{t}(\mathrm{G})=1$ and hence $\mathrm{n}=1$. But $\chi(\mathrm{G})=\mathrm{n}-3=$ negative value. Which is a contradiction. Hence no fuzzy graph exists. If $\mathrm{z}$ is adjacent to $\mathrm{u}_{\mathrm{j}}$ for some $\mathrm{i} \neq \mathrm{j}$ then $\left\{\mathrm{u}_{\mathrm{i}}, \mathrm{u}_{\mathrm{j}}\right\}$ for $\mathrm{i} \neq \mathrm{j}$ is $\gamma_{t}$-set of $\mathrm{G}$, so that $\gamma_{t}(\mathrm{G})=2$ and hence $\mathrm{n}=2$. But $\chi(\mathrm{G})=\mathrm{n}-3=$ negative value. Which is a contradiction. Hence no fuzzy graph exists.

Case (ii) Let $\gamma_{t}(\mathrm{G})=\mathrm{n}-1$ and $\chi(\mathrm{G})=\mathrm{n}-2$.

Since $\chi(\mathrm{G})=\mathrm{n}-2, \mathrm{G}$ contains a clique $\mathrm{K}$ on $\mathrm{n}-2$ vertices. Let $\mathrm{S}=\{\mathrm{x}, \mathrm{y}\} \in \mathrm{V}-\mathrm{S}$. Then $\langle S\rangle=K_{2}$ or $\overline{K_{2}}$

Subcase (a) Let $\langle S\rangle=K_{2}$ Since $\mathrm{G}$ is connected, $\mathrm{x}$ (or equivalently $\mathrm{y})$ is adjacent to some $\mathrm{u}_{\mathrm{i}}$ of $\mathrm{K}_{\mathrm{n}-2}$. Then $\left\{\mathrm{x}, \mathrm{u}_{\mathrm{i}}\right\}$ is $\gamma_{t}$ - set, so that $\gamma_{t}(\mathrm{G})=2$ and hence $\mathrm{n}=3$. But $\chi(\mathrm{G})=\mathrm{n}-2=1$ for which $\mathrm{G}$ is totally disconnected, which is a contradiction. Hence no fuzzy graph exists.

Subcase (b) Let $\langle S\rangle=\overline{K_{2}}$ Since $\mathrm{G}$ is connected, $\mathrm{x}$ is adjacent to some $u_{i}$ of $K_{n-2}$. Then $y$ is adjacent to the same $u_{i}$ of $\mathrm{K}_{\mathrm{n}-2}$. Then $\left\{\mathrm{u}_{\mathrm{i}}\right\}$ is $\gamma_{t}$ - set, so that $\gamma_{t}(\mathrm{G})=1$ and hence $\mathrm{n}=2$. But $\chi(\mathrm{G})=\mathrm{n}-2=0$. Which is a contradiction. Hence no fuzzy 
graph exists. Otherwise $\mathrm{x}$ is adjacent to $\mathrm{u}_{\mathrm{i}}$ of $\mathrm{K}_{\mathrm{n}-2}$ for some $\mathrm{i}$ and $\mathrm{y}$ is adjacent to $\mathrm{u}_{\mathrm{j}}$ of $\mathrm{K}_{\mathrm{n}-2}$ for $\mathrm{i} \neq \mathrm{j}$. In this $\left\{\mathrm{u}_{\mathrm{i}}, \mathrm{u}_{\mathrm{j}}\right\} \gamma_{t}$ - set, so that $\gamma_{t}(\mathrm{G})=2$ and hence $\mathrm{n}=3$. But $\chi(\mathrm{G})=1$ for which $\mathrm{G}$ is totally disconnected. Which is a contradiction. In this case also no fuzzy graph exists.

Case (iii) Let $\gamma_{t}(\mathrm{G})=\mathrm{n}-2$ and $\chi(\mathrm{G})=\mathrm{n}-1$.

Since $\chi(\mathrm{G})=\mathrm{n}-1, \mathrm{G}$ contains a clique $\mathrm{K}$ on $\mathrm{n}-1$ vertices. Let $\mathrm{x}$ be a vertex of $K_{n-1}$. Since $G$ is connected the vertex $x$ is adjacent to one vertex $\mathrm{u}_{\mathrm{i}}$ for some $\mathrm{i}$ in $\mathrm{K}_{\mathrm{n}-1}$ so that $\gamma_{t}(\mathrm{G})=1$, we have $\mathrm{n}=3$ and $\chi=2$.Then $\mathrm{K}=\mathrm{K}_{2}=\mathrm{uv}$. If $\mathrm{x}$ is adjacent to $\mathrm{u}_{\mathrm{i}}$, then $\mathrm{G} \cong \mathrm{P}_{3}$.

Case (iv) Let $\gamma_{t}(\mathrm{G})=\mathrm{n}-3$ and $\chi(\mathrm{G})=\mathrm{n}$

Since $\chi(G)=n, G=K_{n}$, But for $K_{n}, \gamma_{t}(G)=1$, so that $n=4, \chi=4$ Hence $\mathrm{G} \cong \mathrm{K}_{4}$. Converse is obvious.

3.5 Theorem: For any connected fuzzy graph G, $\gamma_{t}(\mathrm{G})+\chi(\mathrm{G})=2 \mathrm{n}-4$ and the equality holds if and only if $\mathrm{G} \cong \mathrm{P}_{4}, \mathrm{~K}_{5}$ or the graph in figure 3.1

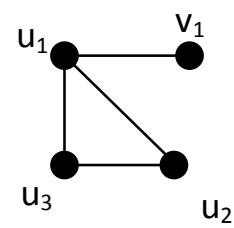

Figure 3.1

Proof: Assume that $\gamma_{t}(\mathrm{G})+\chi(\mathrm{G})=2 \mathrm{n}-4$. This is possible only if $\gamma_{t}(\mathrm{G})=\mathrm{n}$ and $\chi(\mathrm{G})=\mathrm{n}-4$ (or) $\gamma_{t}(\mathrm{G})=\mathrm{n}-1$ and $\chi(\mathrm{G})=\mathrm{n}-3$ (or) $\gamma_{t}(\mathrm{G})=\mathrm{n}-2$ and $\chi(\mathrm{G})=\mathrm{n}-2$ (or) $\gamma_{t}(\mathrm{G})=\mathrm{n}-3$ and $\chi(\mathrm{G})=\mathrm{n}-1$ (or) $\gamma_{t}(\mathrm{G})=\mathrm{n}-4$ and $\chi(\mathrm{G})=\mathrm{n}$.

Case (i) Let $\gamma_{t}(\mathrm{G})=\mathrm{n}$ and $\chi(\mathrm{G})=\mathrm{n}-4$.

Since $\chi(\mathrm{G})=\mathrm{n}-4, \mathrm{G}$ contains a clique $\mathrm{K}$ on $\mathrm{n}-4$ vertices. Let $\mathrm{S}$ $=\left\{\mathrm{v}_{1}, \mathrm{v}_{2}, \mathrm{v}_{3}, \mathrm{v}_{4}\right\}$. Then the induced subgraph $\langle\mathrm{s}\rangle$ has the following possible cases $\mathrm{K}_{4}, \bar{K}_{4}, \mathrm{P}_{4}, \mathrm{P}_{3} \mathrm{UK}_{1}, \mathrm{~K}_{2} \mathrm{UK}_{2}, \mathrm{~K}_{3} \mathrm{UK}_{1}, \mathrm{~K}_{1,3}$

In all the above cases, it can be verified that no new fuzzy graphs exists.

Case(ii) Let $\gamma_{t}(\mathrm{G})=\mathrm{n}-1$ and $\chi(\mathrm{G})=\mathrm{n}-3$.

Since $\chi(\mathrm{G})=\mathrm{n}-3, \mathrm{G}$ contains a clique $\mathrm{K}$ on $\mathrm{n}-3$ vertices. Let $\mathrm{S}=\{\mathrm{x}, \mathrm{y}, \mathrm{z}\} \in \mathrm{V}-\mathrm{S}$. Then $\langle\mathrm{S}\rangle=K_{3}, \overline{K_{3}}, \mathrm{~K}_{2} \cup \mathrm{K}_{1}, \mathrm{P}_{3}$

Subcase (i) Let $\langle S\rangle=K_{3}$. Since $\mathrm{G}$ is connected, $\mathrm{x}$ is adjacent to some $\mathrm{u}_{\mathrm{i}}$ of $\mathrm{K}_{\mathrm{n}-3}$. Then $\left\{\mathrm{x}, \mathrm{u}_{\mathrm{i}}\right\}$ is $\gamma_{t}$ - set, so that $\gamma_{t}(\mathrm{G})=2$ and hence $\mathrm{n}=3$. But $\chi(\mathrm{G})=\mathrm{n}-3=0$. Which is a contradiction. Hence no fuzzy graph exists.

Subcase (ii) Let $\langle S\rangle=\overline{K_{3}}$ Since $\mathrm{G}$ is connected, one of the vertices of $K_{n-3}$ say $u_{i}$ is adjacent to all the vertices of $S$ or two vertices of $S$ or one vertex of $S$. If $u_{i}$ for some $i$ is adjacent to all the vertices of $S$, then $\left\{u_{i}\right\}$ in $K_{n-3}$ is $\gamma_{t}$-set of $\mathrm{G}$. so that $\gamma_{t}(\mathrm{G})=1$ and hence $\mathrm{n}=2$. But $\chi(\mathrm{G})=\mathrm{n}-3=$ negative value. Which is a contradiction. Hence no fuzzy graph exists. If $\mathrm{u}_{\mathrm{i}}$ for some $i$ is adjacent to two vertices of $S$ say $x$ and $y$ then $G$ is connected, $\mathrm{z}$ is adjacent to $\mathrm{u}_{\mathrm{j}}$ for $\mathrm{i} \neq \mathrm{j}$ in $\mathrm{K}_{\mathrm{n}-3}$, then $\left\{\mathrm{u}_{\mathrm{i}}, \mathrm{u}_{\mathrm{j}}\right\}$ in
$\mathrm{K}_{\mathrm{n}-3}$ is $\gamma_{t}$-set of $\mathrm{G}$, so that $\gamma_{t}(\mathrm{G})=2$ and hence $\mathrm{n}=3$. But $\chi(\mathrm{G})=\mathrm{n}-3=0$. Which is a contradiction. Hence no fuzzy graph exists. If $u_{i}$ for some $i$ is adjacent to $x$ and $u_{j}$ is adjacent to $y$ and $\mathrm{u}_{\mathrm{k}}$ is adjacent to $\mathrm{z}$, then $\left\{\mathrm{u}_{\mathrm{i}}, \mathrm{u}_{\mathrm{j}}, \mathrm{u}_{\mathrm{k}}\right\}$ for $\mathrm{i} \neq \mathrm{j} \neq \mathrm{k}$ in $\mathrm{K}_{\mathrm{n}-3}$ is $\gamma_{t}$ set of $\mathrm{G}$. so that $\gamma_{t}(\mathrm{G})=3$ and hence $\mathrm{n}=4$. But $\chi(\mathrm{G})=1$ for which $\mathrm{G}$ is totally disconnected. Which is a contradiction. Hence no fuzzy graph exists.

Subcase (iii) Let $\langle S\rangle=\mathrm{P}_{3}=\{x, y, z\}$. Since $\mathrm{G}$ is connected, $x$ (or equivalently $z$ ) is adjacent to $u_{i}$ for some $i$ in $\mathrm{K}_{\mathrm{n}-3}$. Then $\left\{\mathrm{x}, \mathrm{y}, \mathrm{u}_{\mathrm{i}}\right\}$ is $\gamma_{t}$-set of $\mathrm{G}$. so that $\gamma_{t}(\mathrm{G})=3$ and hence $\mathrm{n}=4$. But $\chi(\mathrm{G})=\mathrm{n}-3=1$. Which is a contradiction. Hence no fuzzy graph exists. If $\mathrm{u}_{\mathrm{i}}$ is adjacent to $\mathrm{y}$ then $\left\{\mathrm{u}_{\mathrm{i}}, \mathrm{y}\right\}$ is $\gamma_{t}$-set of G. so that $\gamma_{t}(\mathrm{G})=2$ and hence $\mathrm{n}=3$. But $\chi(\mathrm{G})=\mathrm{n}-3=0$. Which is a contradiction. Hence no fuzzy graph exists.

Subcase (iv) Let $\langle S\rangle=\mathrm{K}_{2} \cup \mathrm{K}_{1}$ Let $\mathrm{xy}$ be the edge and $\mathrm{z}$ be a isolated vertex of $K_{2} \cup K_{1}$ Since $G$ is connected, there exists $\mathrm{a} \mathrm{u}_{\mathrm{i}}$ in $\mathrm{K}_{\mathrm{n}-3}$ is adjacent to $\mathrm{x}$ and $\mathrm{z}$ also adjacent to same $\mathrm{u}_{\mathrm{i}}$ Then $\left\{\mathrm{u}_{\mathrm{i}}\right\}$ is a $\gamma_{t}$-set of $\mathrm{G}$. So that $\gamma_{t}(\mathrm{G})=1$ and hence $\mathrm{n}=2$. But $\chi(\mathrm{G})=\mathrm{n}-3=$ negative value. Which is a contradiction. Hence no fuzzy graph exists. If $\mathrm{z}$ is adjacent to $\mathrm{u}_{\mathrm{j}}$ for some $\mathrm{i} \neq \mathrm{j}$ then $\left\{\mathrm{u}_{\mathrm{i}}, \mathrm{u}_{\mathrm{j}}\right\}$ for $\mathrm{i} \neq \mathrm{j}$ is a is a $\gamma_{t}$-set of $\mathrm{G}$. so that $\gamma_{t}(\mathrm{G})=2$ and hence $\mathrm{n}=3$. But $\chi(\mathrm{G})=\mathrm{n}-3=0$. Which is a contradiction. Hence no fuzzy graph exists.

Case (iii) Let $\gamma_{t}(\mathrm{G})=\mathrm{n}-2$ and $\chi(\mathrm{G})=\mathrm{n}-2$.

Since $\chi(\mathrm{G})=\mathrm{n}-2$, $\mathrm{G}$ contains a clique $\mathrm{K}$ on $\mathrm{n}-2$ vertices. Let $\mathrm{S}=\{\mathrm{x}, \mathrm{y}\} \in \mathrm{V}-\mathrm{S}$. Then $\langle S\rangle=K_{2}$ or $\overline{K_{2}}$

Subcase (a) Let $\langle S\rangle=K_{2}$. Since $\mathrm{G}$ is connected, $\mathrm{x}$ (or equivalently $\mathrm{y})$ is adjacent to some $\mathrm{u}_{\mathrm{i}}$ of $\mathrm{K}_{\mathrm{n}-2}$. Then $\left\{\mathrm{x}, \mathrm{u}_{\mathrm{i}}\right\}$ is $\gamma_{t}$ - set, so that $\gamma_{t}(\mathrm{G})=2$ and hence $\mathrm{n}=4$. But $\chi(\mathrm{G})=\mathrm{n}-2=2$. Then $\mathrm{G} \cong \mathrm{P}_{4}$.

Subcase (b) Let $\langle S\rangle=\overline{K_{2}}$, since $\mathrm{G}$ is connected, $\mathrm{x}$ is adjacent to some $u_{i}$ of $K_{n-2}$. Then $y$ is adjacent to the same $u_{i}$ of $\mathrm{K}_{\mathrm{n}-2 .}$. Then $\left\{\mathrm{u}_{\mathrm{i}}\right\}$ is $\gamma_{t}$ - set, so that $\gamma_{t}(\mathrm{G})=1$ and hence $\mathrm{n}=3$. But $\chi(\mathrm{G})=\mathrm{n}-2=1$. Which is a contradiction. Hence no fuzzy graph exists, or $\mathrm{y}$ is adjacent to $\mathrm{u}_{\mathrm{j}}$ of $\mathrm{K}_{\mathrm{n}-2}$ for $\mathrm{i} \neq \mathrm{j}$. In this $\left\{\mathrm{u}_{\mathrm{i}}, \mathrm{u}_{\mathrm{j}}\right\}$ is $\gamma_{t}-$ set, so that $\gamma_{t}(\mathrm{G})=2$ and hence $\mathrm{n}=4$. But $\chi(\mathrm{G})=2$. Then $\mathrm{G} \cong \mathrm{P}_{4}$.

Case (iv) Let $\gamma_{t}(\mathrm{G})=\mathrm{n}-3$ and $\chi(\mathrm{G})=\mathrm{n}-1$.

Since $\chi(\mathrm{G})=\mathrm{n}-1, \mathrm{G}$ contains a clique $\mathrm{K}$ on $\mathrm{n}-1$ vertices. Let $\mathrm{x}$ be a vertex of $\mathrm{G}-\mathrm{K}_{\mathrm{n}-1}$. Since $\mathrm{G}$ is connected the vertex $\mathrm{x}$ is adjacent to one vertex $u_{i}$ for some $i$ in $K_{n-1}$, so that $\gamma_{t}(G)=1$, we have $\mathrm{n}=4$ and $\chi=3$. Then $\mathrm{K}=\mathrm{K}_{3}$ Let $\mathrm{u}_{1}, \mathrm{u}_{2}, \mathrm{u}_{3}$ be the vertices of $K_{3}$. Then $x$ must be adjacent to only one vertex of $\mathrm{G}-\mathrm{K}_{3}$. Without loss of generality let $\mathrm{x}$ be adjacent to $\mathrm{u}_{1}$.If $\mathrm{d}(\mathrm{x})=1$, then $\mathrm{G} \cong \mathrm{G}_{1}$. (in Fig 2.1)

Case (v) Let $\gamma_{t}(\mathrm{G})=\mathrm{n}-4$ and $\chi(\mathrm{G})=\mathrm{n}$

Since $\chi(\mathrm{G})=\mathrm{n}, \mathrm{G}=\mathrm{K}_{\mathrm{n}}$, But for $\mathrm{K}_{\mathrm{n}}, \gamma_{\mathrm{t}}(\mathrm{G})=1$, so that $\mathrm{n}=5, \chi=5$. Hence $\mathrm{G} \cong \mathrm{K}_{5}$. Converse is obvious.

Theorem 2.6 For any connected fuzzy graph $\mathrm{G}, \gamma_{t}(\mathrm{G})+$ $\chi(\mathrm{G})=2 \mathrm{n}-5$ for any $\mathrm{n}>4$, if and only if $\mathrm{G}$ is isomorphic to $\mathrm{K}_{6}, \mathrm{~K}_{3}\left(\mathrm{P}_{3}\right), \mathrm{K}_{3}(1,1,0), \mathrm{P}_{5}, \mathrm{~K}_{4}(1,0,0,0), \mathrm{K}_{1,3}$ (or) any one of the following fuzzy graphs in the figure 3.2 . 


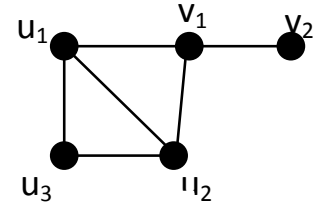

$\mathrm{G}_{1}$

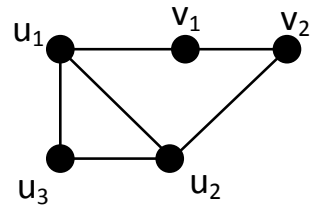

$\mathrm{G}_{2}$

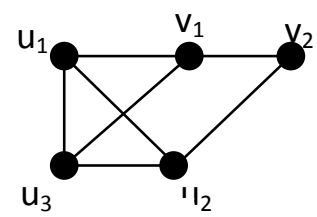

$\mathrm{G}_{3}$

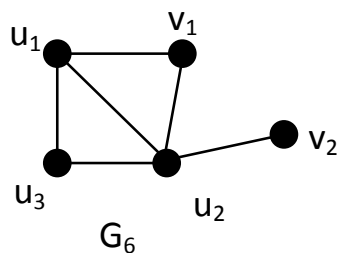

$\mathrm{G}_{6}$

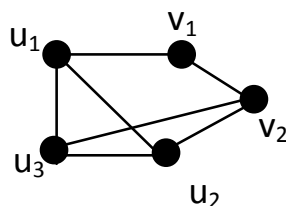

$\mathrm{G}_{4}$

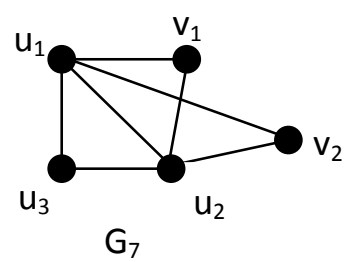

$\mathrm{G}_{7}$

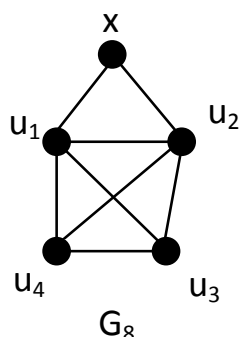

Figure 3.2

Proof: If $\mathrm{G}$ is any one or une grapus in the theorem, then it can be verified that $\gamma_{t}(\mathrm{G})+\chi(\mathrm{G})=2 \mathrm{n}-5$. Conversely set $\gamma_{t}(\mathrm{G})+\chi(\mathrm{G})=2 \mathrm{n}-5$ then $\gamma_{t}(\mathrm{G})=\mathrm{n}$ and $\chi(\mathrm{G})=\mathrm{n}-5$ (or) $\gamma_{t}(\mathrm{G})=\mathrm{n}-$ 1 and $\chi(\mathrm{G})=\mathrm{n}-4$ (or) $\gamma_{t}(\mathrm{G})=\mathrm{n}-2$ and $\chi(\mathrm{G})=\mathrm{n}-3$ (or) $\gamma_{t}(\mathrm{G})=\mathrm{n}-3$ and $\chi(\mathrm{G})=\mathrm{n}-2$ (or) $\gamma_{t}(\mathrm{G})=\mathrm{n}-4$ and $\chi(\mathrm{G})=\mathrm{n}-1$ (or) $\gamma_{t}(\mathrm{G})=\mathrm{n}-5$ and $\chi(\mathrm{G})=\mathrm{n}$

Case (i): Let $\gamma_{t}(\mathrm{G})=\mathrm{n}$ and $\chi(\mathrm{G})=\mathrm{n}-5$

Since $\chi(\mathrm{G})=\mathrm{n}-5, \mathrm{G}$ contains a clique $\mathrm{K}$ in $\mathrm{n}-5$ vertices (or) does not contain a clique $K$ on $n-5$ vertices. Let $\mathrm{S}=\left\{\mathrm{v}_{1}, \mathrm{v}_{2}, \mathrm{v}_{3}, \mathrm{v}_{4}, \mathrm{v}_{5}\right\}$. Then the induced subgraph $\langle\mathrm{S}\rangle$ has the following possible cases. $\mathrm{K}_{5}, \bar{K}_{5}, \mathrm{P}_{5}, \mathrm{P}_{3} \cup \mathrm{P}_{2}, \mathrm{P}_{3} \mathrm{U}$ $\bar{K}_{2}, \mathrm{~K}_{4} \cup K_{1}, \mathrm{P}_{4} \cup K_{1}, \mathrm{~K}_{3} \cup K_{2}, \mathrm{~K}_{3} \cup \bar{K}_{2}$.

In all the above cases, it can be verified that no new fuzzy graph exists.

\section{Case (ii): Let $\gamma_{\mathrm{t}}(\mathrm{G})=\mathrm{n}-1$ and $\chi(\mathrm{G})=\mathrm{n}-4$.}

Since $\chi(\mathrm{G})=\mathrm{n}-4 \mathrm{G}$ contains a clique $\mathrm{K}$ on $\mathrm{n}-4$ vertices. Let $\mathrm{S}=\left\{\mathrm{v}_{1}, \mathrm{v}_{2}, \mathrm{v}_{3}, \mathrm{v}_{4}\right\}$. Then the induced subgraph $\langle\mathrm{s}\rangle$ has the following possible cases $\mathrm{K}_{4}, \bar{K}_{4}, \mathrm{P}_{4}, \mathrm{P}_{3} \mathrm{UK}_{1}, \mathrm{~K}_{2} \mathrm{UK}_{2}, \mathrm{~K}_{3} \mathrm{UK}_{1}$
In all the above cases, it can be verified that no new fuzzy graph exists.

Case (iii): Let $\gamma_{\mathrm{t}}(\mathrm{G})=\mathrm{n}-2$ and $\chi(\mathrm{G})=\mathrm{n}-3$.

Since $\chi(\mathrm{G})=\mathrm{n}-3, \mathrm{G}$ contains a clique with $\mathrm{n}-3$ vertices. Let $\mathrm{S}$ $=\left\{\mathrm{v}_{1}, \mathrm{v}_{2}, \mathrm{v}_{3}\right\}$ Then the induced subgraph $\langle\mathrm{S}\rangle$ has the following possible cases $\mathrm{K}_{3}, \bar{K}_{3}, \mathrm{~K}_{2} \cup \mathrm{K}_{1}, \mathrm{P}_{3}$.

Subcase (i): Let $\langle\mathrm{S}\rangle=\mathrm{K}_{3}$. Since $\mathrm{G}$ is connected there exists a vertex $u_{i}$ in $K_{n-3}$ which is adjacent to any one of $\left\{v_{1}, v_{2}, v_{3}\right\}$ without loss of generality let $\mathrm{u}_{\mathrm{i}}$ be adjacent to $\mathrm{v}_{1}$, then $\left\{\mathrm{v}_{1}, \mathrm{u}_{\mathrm{j}}\right\}$ is $\gamma_{\mathrm{t}}$ - set of $\mathrm{G}$, so that $\mathrm{n}=4$. But $\chi(\mathrm{G})=1$ which is a contradiction. Hence no graph exists.

Subcase (ii): Let $\langle\mathrm{S}\rangle=\bar{K}_{3}$. Let $\left\{\mathrm{v}_{1}, \mathrm{v}_{2}, \mathrm{v}_{3}\right\}$ be the vertices of $\bar{K}_{3}$. Since $\mathrm{G}$ is connected all the vertices of $\bar{K}_{3}$ are adjacent to one vertex say $\mathrm{u}_{\mathrm{i}}$, in $\mathrm{K}_{\mathrm{n}-3}$ (or) 2 vertices of $\bar{K}_{3}$ are adjacent to the vertex $\mathrm{u}_{\mathrm{i}}$ and remaining one vertex of $\bar{K}_{3}$ is adjacent to $\mathrm{u}_{\mathrm{j}}$ for $\mathrm{i} \neq \mathrm{j}$ inK $\mathrm{n}_{\mathrm{n}-3}$ (or) all the vertices of $\bar{K}_{3}$ are adjacent to the distinct vertices of $\mathrm{K}_{\mathrm{n}-3}$. If all the vertices of $\bar{K}_{3}$ are adjacent to one vertex say $u_{i}$ in $K_{n-3}$, the $\left\{v_{1}, u_{i}\right\}$ is $\gamma_{t}$ - set of $G$, so that $n=$ $4, \chi(\mathrm{G})=1$ which is a contradiction. Hence no fuzzy graph exists. If two vertices of $\bar{K}_{3}$ are adjacent to the vertex $\mathrm{u}_{\mathrm{i}}$ and the remaining one is adjacent to $\mathrm{u}_{\mathrm{j}} \mathrm{i} \neq \mathrm{j}$ in $\mathrm{K}_{\mathrm{n}-3}$ then $\left\{\mathrm{u}_{\mathrm{i}}, \mathrm{u}_{\mathrm{j}}, \mathrm{v}_{3}\right\}$ is $\gamma_{t}$-set of G. So that $\mathrm{n}=4$ which is a contradiction. Hence no graphs exists. If all the vertices of $\bar{K}_{3}$ are adjacent to the vertices $u_{i}, u_{j}, u_{k} i \neq j \neq k$ respectively. Then $\left\{u_{i}, u_{j}, v_{3}\right\}$ is $\gamma_{t}$-set of $\mathrm{G}$. Hence $\mathrm{n}=5, \chi(\mathrm{G})=2$ which is a contradiction. Hence no graph exists.

Subcase (iii): Let $\langle\mathrm{S}\rangle=\mathrm{P}_{3}$. Since $\mathrm{G}$ is connected there exists a vertex $u_{i}$ is adjacent to any one of $\left\{v_{1}, v_{3}\right\}$ or $v_{2}$. If $u_{i}$ is adjacent to any of the $\left\{\mathrm{v}_{1}, \mathrm{v}_{3}\right\}$, then $\left\{\mathrm{v}_{1}, \mathrm{v}_{2}, \mathrm{u}_{\mathrm{i}}\right\}$ is $\gamma_{t}$-set of $\mathrm{G}$. Hence $n=5$ so that $K=K_{2}$. Let $u_{1}, u_{2}$ are the vertices of $K_{2}$. Let $\mathrm{v}_{1}$ be adjacent to $\mathrm{u}_{\mathrm{i}}$ and if $\mathrm{d}\left(\mathrm{v}_{1}\right)=\mathrm{d}\left(\mathrm{v}_{2}\right)=2, \mathrm{~d}\left(\mathrm{v}_{3}\right)=1$ then $\mathrm{G} \cong \mathrm{P}_{5}$ If $v_{2}$ is adjacent to $u_{i}$ then $\left\{u_{i}, v_{2}\right\}$ is $\gamma_{t}$ - set of G. Hence $n=4$ $\chi(\mathrm{G})=1$ which is a contradiction. Hence no graph exists. If the degree of the vertices is increased then no new fuzzy graphs exists.

Subcase (iv): Let $\langle\mathrm{S}\rangle=\mathrm{K}_{2} \cup \mathrm{K}_{1}$. Let $\left\{\mathrm{v}_{1}, \mathrm{v}_{2}\right\}$ be the vertices of $K_{2}$ and $v_{3}$ be the isolated vertex. Since $G$ is connected, there exists a vertex $u_{i}$ is adjacent to any one of $\left\{v_{1}, v_{2}\right\}$ and $v_{3}$ (or) $\mathrm{u}_{\mathrm{i}}$ is adjacent to any one of $\left\{\mathrm{v}_{1}, \mathrm{v}_{2}\right\}$ and $\mathrm{u}_{\mathrm{j}}$ for $\mathrm{i} \neq \mathrm{j}$ is adjacent to $\mathrm{v}_{3}$. If $\mathrm{u}_{\mathrm{i}}$ is adjacent to any one of $\left\{\mathrm{v}_{1}, \mathrm{v}_{2}\right\}$ and $\mathrm{v}_{3},\left\{\mathrm{u}_{\mathrm{i}}, \mathrm{v}_{1}\right\}$ is $\gamma_{t}$ set of $\mathrm{G}$. Hence $\mathrm{n}=4$ and $\chi(\mathrm{G})=1$ which is a contradiction. Hence no graph exists.

If $u_{i}$ is adjacent to any one of $\left\{v_{1}, v_{2}\right\}$ and $u_{j} j \neq i$ is adjacent to $\mathrm{v}_{3}$. In this case $\left\{\mathrm{v}_{1}, \mathrm{u}_{\mathrm{i}}, \mathrm{u}_{\mathrm{j}}\right\}$ is $\gamma_{t}$-set of G. Hence $\mathrm{n}=5, \chi(\mathrm{G})=2$. Then $\mathrm{G} \cong \mathrm{P}_{5}$.If the degree of the vertices is increased then no new fuzzy graphs exists.

Case (iv): Let $\gamma_{t}(\mathrm{G})=\mathrm{n}-3, \chi(\mathrm{G})=\mathrm{n}-2$.

Since $\chi(\mathrm{G})=\mathrm{n}-2, \mathrm{G}$ contains a clique $\mathrm{K}$ on $\mathrm{n}-2$ vertices. If $\mathrm{G}$ contains a clique $K$ on $n-2$ vertices. Let $S=\left\{v_{1}, v_{2}\right\} \in V(G)$ $\mathrm{V}(\mathrm{K})$. Then the induced sub graph $\langle\mathrm{S}\rangle$ has the following possible cases.

Subcase (i): Let $\langle\mathrm{S}\rangle=\mathrm{K}_{2}$. Since $\mathrm{G}$ is connected, there exists a vertex $u_{i}$ in $K_{n-2}$ is adjacent to any one of $\left\{v_{1}, v_{2}\right\}$. Then $\left\{\mathrm{u}_{\mathrm{i}}, \mathrm{v}_{1}\right\}$ is a $\gamma_{t}$-set of G. Hence $\gamma_{t}(\mathrm{G})=2$, so that $\mathrm{n}=5, \chi(\mathrm{G})=3$. Hence $\mathrm{K} \cong \mathrm{K}_{3}$. Let $\mathrm{u}_{1}, \mathrm{u}_{2}, \mathrm{u}_{3}$ be the vertices of $\mathrm{K}_{3}$. Let $\mathrm{u}_{1}$ be adjacent to $\mathrm{v}_{\mathrm{i}}$. 
If $\mathrm{d}\left(\mathrm{v}_{1}\right)=2 \mathrm{~d}\left(\mathrm{v}_{2}\right)=1$ then $\mathrm{G} \cong \mathrm{K}_{3}\left(\mathrm{P}_{3}\right)$ If $\mathrm{d}\left(\mathrm{v}_{1}\right)=3 \mathrm{~d}\left(\mathrm{v}_{2}\right)=1 \mathrm{G} \cong \mathrm{G}_{1}$ Let $\mathrm{u}_{1}$ be adjacent to $\mathrm{v}_{1}$ and $\mathrm{u}_{2}$ be adjacent to $\mathrm{v}_{2}$. If $\mathrm{d}\left(\mathrm{v}_{1}\right)=\mathrm{d}\left(\mathrm{v}_{2}\right)=2$ the $\mathrm{n} \mathrm{G} \cong \mathrm{G}_{2}$ If $\mathrm{d}\left(\mathrm{v}_{1}\right)=3 \mathrm{~d}\left(\mathrm{v}_{2}\right)=2$ then $\mathrm{G} \cong \mathrm{G}_{3}$ If $d\left(v_{1}\right)=2, d\left(v_{2}\right)=3$ then $G \cong G_{4}$. If the degree of the vertices is increased then no new fuzzy graphs exists.

Subcase (ii): Let $\langle\mathrm{S}\rangle=\bar{K}_{2}$. Since $\mathrm{G}$ is connected all the vertices of $\bar{K}_{2}$ are adjacent to one vertex say $\mathrm{u}_{\mathrm{i}}$ in $\mathrm{K}_{\mathrm{n}-2}$ (or) distinct vertices in $\mathrm{K}_{\mathrm{n}-2}$. If all the vertices of $\bar{K}_{2}$ are adjacent to one vertex say $u_{i}$ in $\mathrm{K}_{\mathrm{n}-2}$. In this case $\left\{\mathrm{u}_{\mathrm{i}}\right\}$ is $\gamma_{t}$-set of G. Since $\gamma_{t}(\mathrm{G})=1$ so that $\mathrm{n}=4 \chi(\mathrm{G})=2$. Hence $\mathrm{K} \cong \mathrm{K}_{2}$. Let $\mathrm{u}_{1}, \mathrm{u}_{2}$ be the vertices of $K_{2}$. Let $u_{1}$ be adjacent to both $v_{1}$ and $v_{2}$ then $\mathrm{G} \cong \mathrm{K}_{1,3}$. If the two vertices of $\bar{K}_{2}$ are adjacent to the distinct of $\mathrm{K}_{\mathrm{n}-2}$. In this case $\left\{\mathrm{u}_{\mathrm{i}}, \mathrm{u}_{\mathrm{j}}\right\}$ for $\mathrm{i} \neq \mathrm{j}$ forms $\gamma_{t}$ - set of $\mathrm{G}$. Hence $\mathrm{n}=5, \chi(\mathrm{G})=3$. So that $\mathrm{K} \cong \mathrm{K}_{3}$. Let $\left\{\mathrm{u}_{1}, \mathrm{u}_{2}, \mathrm{u}_{3}\right\}$ be the vertices of $\mathrm{K}_{3}$. Let $\mathrm{u}_{1}$ be adjacent to $\mathrm{v}_{1}$ and $\mathrm{u}_{2}$ be adjacent to $\mathrm{v}_{2}$ then $\mathrm{G} \cong \mathrm{K}_{3}(1,1,0)$. If $\mathrm{d}\left(\mathrm{v}_{1}\right)=1$ and $\mathrm{d}\left(\mathrm{v}_{2}\right)=2$ than $\mathrm{G} \cong \mathrm{G}_{5}$. If $\mathrm{d}\left(\mathrm{v}_{1}\right)=2$ $d\left(v_{2}\right)=1$ then $G \cong G_{6}$ If $d\left(v_{1}\right)=2 d\left(v_{2}\right)=2$ then $G \cong G_{7}$. If the degree of the vertices is increased then no new fuzzy graphs exists.

\section{Case (v): Let $\gamma_{t}(\mathrm{G})=\mathrm{n}-4 \chi(\mathrm{G})=\mathrm{n}-1$}

Since $\chi(\mathrm{G})=\mathrm{n}-1, \mathrm{G}$ contains a clique $\mathrm{K}$ on $\mathrm{n}-1$ vertices. Let $\mathrm{x}$ be a vertex of $G-K_{n-1}$. Since $G$ is connected the vertex $x$ is adjacent to one vertex $\mathrm{u}_{\mathrm{i}}$ of $\mathrm{K}_{\mathrm{n}-1}$ so that $\gamma_{t}(\mathrm{G})=1$. Hence $\mathrm{n}=5$ $\chi(\mathrm{G})=4$, so that $\mathrm{K} \cong \mathrm{K}_{4}$. Let $\left\{\mathrm{u}_{1}, \mathrm{u}_{2} \mathrm{u}_{3}, \mathrm{u}_{4}\right\}$ be the vertices of $\mathrm{K}_{4}$. Without loss of generality let $\mathrm{x}$ be adjacent to $\mathrm{u}_{1}$, of $\mathrm{K}_{4}$, then $G \cong K_{4}\left(P_{2}\right)$. If $d\left(v_{1}\right)=2$ then $G \cong G_{8}$. If $d\left(v_{1}\right)=3$ then $G \cong G_{9}$

Case (vi): Let $\gamma_{t}(\mathrm{G})=\mathrm{n}-5 \chi(\mathrm{G})=\mathrm{n}$

Since $\chi(\mathrm{G})=\mathrm{n}, \mathrm{G} \cong \mathrm{Kn}$. But for $\mathrm{K}_{\mathrm{n}} \gamma_{t}(\mathrm{G})=1$, so that $\mathrm{n}=6$. Hence $\mathrm{G} \cong \mathrm{K}_{6}$.

\section{CONCLUSION}

In this paper, upper bound of the sum of total domination and chromatic number is proved. In future this result can be extended to various domination parameters. The structure of the graphs had been given in this paper can be used in models and networks. The authors have obtained similar results with large cases of graphs for which $\gamma_{t}(\mathrm{G})+\chi(\mathrm{G})=2 \mathrm{n}-6$, $\gamma_{\boldsymbol{t}}(\mathrm{G})+\chi(\mathrm{G})=2 \mathrm{n}-7, \gamma_{\boldsymbol{t}}(\mathrm{G})+\chi(\mathrm{G})=2 \mathrm{n}-8$

\section{ACKNOWLEDGMENTS}

We extend our thanks the Lord Almighty to give the knowledge to do this work.

\section{REFERENCES}

[1] Teresa W. Haynes, Stephen T. Hedemiemi and Peter J. Slater (1998), fundamentals of Domination in graphs, Marcel Dekker, Newyork.
[2] Hanary F and Teresa W. Haynes,(2000), Double Domination in graphs, ARC Combinatoria 55, pp. 201213

[3] Haynes, Teresa W.(2001): Paired domination in Graphs, Congr. Number 150

[4] Mahadevan G, Selvam A, (2008): On independent domination number and chromatic number of a graph, Acta Ciencia Indica, preprint

[5] Paulraj Joseph J. and Arumugam S.(1992): Domination and connectivity in graphs, International Journal of Management and systems, 8 No.3: 233-236.

[6] Kaufmann.A., (1975), Introduction to the theory of Fuzzy Subsets, Academic Press, Newyork.

[7]Rosenfield,A., Fuzzy graphs In: Zadeh, L.A., Fu, K.S., Shimura, M.(Eds), Fuzzy sets and their applications(Academic Press, New York)

[8]Somasundaram.A, Somasundaram,S. 1998, Domination in Fuzzy Graphs - I, Pattern Recognition Letters, 19, pp787-791.

[9]Somasundaram.A, (2004), Domination in Fuzzy Graphs II, Journal of Fuzzy Mathematics, 20.

[10]Somasundaram.A, (2005), Domination in Product of Fuzzy Graphs, "International Journal of Uncertainity" , Fuzziness and Knowledge-Based Syatems, 13(2), pp.195-205.

[11]Zadeh,L.A.(1971), Similarity Relations and Fuzzy Ordering, Information sciences, 3(2),pp.177-200.

[12] Mahadevan G,(2005): On domination theory and related concepts in graphs, Ph.D. thesis, Manonmaniam Sundaranar University, Tirunelveli,India.

[13] Paulraj Joseph J. and Arumugam S.(1997): Domination and colouring in graphs. International Journal of Management and Systems, Vol.8 No.1, 37-44.

[14] Paulraj Joseph J, Mahadevan G, Selvam A (2004). On Complementary Perfect domination number of a graph, Acta Ciencia India, vol. XXXIM, No.2,847(2006).

[15] Vimala S, Sathya J.S, "Graphs whose sum of Chromatic number and Total domination equals to $2 \mathrm{n}-5$ for any $n>4$ ", Proceedings of the Heber International Conference on Applications of Mathematics and statistics, Tiruchirappalli pp 375-381

[16] Tamizh Chelvam $\mathrm{T}$ and Jaya Prasad B.(2004): On independent domination number, Referred Proceedings of the National conference on Graph theory and its applications, conducted by Anna University, edited by R.Balakrishnan. Prof Wilson, and G.Setheraman, 108111, Narosa publishing House, New Delhi, India pp. 108-11 